\title{
Gıda Ambalajlarındaki Etiket Bilgilerine ve Logolara Yönelik Tüketici Duyarlılığı: Samsun İli Örneği, Türkiye
}

\author{
Osman KILIÇ ${ }^{*}$, Gamze AYDIN ERYILMAZ ${ }^{2}$ \\ ${ }^{I}$ Ondokuz Mayıs Üniversitesi, Ziraat Fakültesi, Tarım Ekonomisi Bölümü, Samsun, TÜRKIYYE \\ ${ }^{2}$ Ondokuz Mayls Üniversitesi, Samsun Meslek Yüksekokulu, Park ve Bahçe Bitkileri Bölümü, Samsun, TÜRKIYYE
}

\begin{tabular}{ll}
\hline \multicolumn{1}{c}{ Geliş Tarihi/Received: 11.08 .2021} & Kabul Tarihi/Accepted: 17.11 .2021 \\
\hline ORCID ID (Yazar surasına göre / by author order) \\
(D) orcid.org/0000-0002-0129-4034 (Dorcid.org/0000-0002-4440-8687 \\
"Sorumlu Yazar/Corresponding Author: okilic@omu.edu.tr
\end{tabular}

Öz: Günümüzün değişen sosyo-ekonomik koşulları ve artan gıda kaynaklı rahatsılılklar, toplumsal bilinçlenmeyi ve tüketicilerin gıda satın alırken daha duyarlı olmalarını sağlamaktadır. Bu araştırmanın amacı, tüketicilerin gıda satın alma kararında önemli oranda etkisi olan ambalajlardaki etiket bilgilerine ve logolara yönelik tüketici duyarlılığının tespit edilmesidir. Araştırma materyalini, Samsun ili kentsel alanda ikamet eden 384 tüketiciyle yapılan anketlerden elde edilen veriler oluşturmaktadır. Araştırma sonuçları; son kullanma tarihi (4.50), ambalaj dayanıklılığı (4.11) ve ürün adı (3.92) tüketicilerin gıda satın alırken en fazla dikkat ettikleri konular olduğunu göstermektedir. Tüketicilerin gıda ambalajı üzerindeki logolardan en fazla bildikleri; Türk Standardları Enstitüsü (TSE) (\% 31.8), helal gıda (\% 26.6) ve geri kazanılabilir ambalaj (\% 25.3) olarak belirlenmiştir. Gıda ambalajlarındaki etiket bilgileri ve logolar, tüketicilerin satın alma kararlarında en kolay ulașılabilir bilgilendirme araçlarıdır. Bu nedenle etiket bilgileri ve logolar, tüketicilerin geneli tarafindan doğru anlaşılabilir nitelikte olmalıdır. Bu konuda tüketicilerin bilinçlendirilmesinde, günümüzde yaygın olarak kullanılan kitle iletişim araçlarından daha fazla yararlanılabilir. Ayrıca tüketiciler arasındaki geniş iletişim ağının sağladığı gücün dikkate alınması ve tüketici beklentilerine odaklı pazarlama anlayışının belirlenmesi, gıda üreticisi firmalara önemli rekabet üstünlüğü sağlayacaktır

Anahtar Kelimeler: Gıda, ambalaj, etiket bilgisi, logo, tüketici duyarlılığı

\section{Consumer Sensitivity Towards Label Information and Logos on Food Packages: A Case of Samsun Province, Turkey}

\begin{abstract}
Today's changing socio-economic conditions and increasing food related disorders provide social awareness and consumers to be more sensitive when purchasing food. The aim of this research is to determine the consumer sensitivity towards the label information and logos on the packages, which have a significant impact on the consumers' food purchasing decision. The research material consists of the data obtained from the surveys conducted with 384 consumers residing in the urban area of Samsun. The results showed that expiration date (4.50), packaging durability (4.11) and brand name (3.92) were the subjects that consumers pay the most attention when purchasing food. TSE (Turkish Standards Institution) (31.8\%), halal food $(26.6 \%)$ and recyclable packaging $(25.3 \%)$ are the most known logos on food packaging by consumers. Label information and logos on food packages are the most easily accessible information tools for consumers in their purchasing decisions. For this reason, label information and logos must be accurately understandable by the general consumer. Mass media, which are widely used today, can be used intensively in raising awareness of consumers in this regard. In addition, taking into account the power provided by the wide communication network among consumers and determining a marketing approach focused on consumer expectations will provide a significant competitive advantage to food manufacturers.
\end{abstract}




\section{Giriş}

Tüketicilerin gıda ürünleri satın alırken ambalaj üzerindeki etiket bilgilerine ve logolara dikkat etme durumları; kültürel yapı, yaşam tarzı, deneyim ve ekonomik koşullar gibi faktörlere bağlı olarak farklılık göstermektedir. Tüketicinin bir ürünü satın almadaki karar sürecine, satın alma ve tüketme eylemlerinin yanı sıra, tüketicinin ürünle ilgili tüketim sonrasında oluşan tatmin düzeyi de dâhildir. Ürün sayısı ve çeşidi arttıkça, tüketicilerin bir ürünü satın almadaki karar verme süreci daha uzun zaman almaktadır. Bu nedenle tüketiciler, özellikle alternatif ürünlerden birini seçmek durumunda kaldıklarında, ürünlerin ambalaj özellikleri ve etiket bilgilerinden faydalanmaktadır.

Ambalaj; ürünün temiz ve sağlam kalmasını sağlayan, ürünü muhafaza ederek raf ömrünü uzatan ve ürünün albenisini artırarak tüketicilerin dikkatini çeken önemli bir araçtır. Bir ürünün ambalaj1 üzerindeki etikette; ürünün ad1, içindekiler, net miktar, firmanın adı ve adresi, üretildiği yer, üretim ve son kullanma tarihi gibi bilgiler yer almaktadır. Akgüngör ve ark. (2011)'na göre g1da etiketlerinin içerdiği bilgiler, bireylerin daha sağlıklı beslenmesine yardımcı olmakta, beslenme konusundaki farkındalığı artırmakta ve uzun dönemde bilinçli beslenmeyi sağlayarak sağlıklı bireylerden oluşan bir toplumun meydana gelmesine katkıda bulunmaktadır.

Bir ürüne ait etiket bilgileri, tüketicinin o ürünü satın almasında kolay ve hizlı karar vermesini sağlamalıdır. Etikette yer alan bilgi ve semboller, ürünün satın alınması için tüketicinin dikkatini çekmeye yönelik olmasının yanı sıra, ürünle ilgili doğru bilgi veren araçlar olmaları nedeniyle pazarlamada önemli bir fonksiyona sahiptir. Etiket, 26.01.2017 tarihinde yayınlanan Türk Gıda Kodeksi Gıda Etiketleme ve Tüketicileri Bilgilendirme Yönetmeliği'nin 4. maddesinin $\mathrm{h}$ bendinde "Gidanın ambalajının veya kabının üzerine yazılmış, basılmış, şablon ile basılmış, işaretlenmiş, kabartma ile işlenmiş, soğuk baskı ile basılmış, yapıştırılmış veya iliştirilmiş olan herhangi bir işareti, markayl, damgayl, resimli veya diğer tanımlayıcı unsurları ifade eder" şeklinde tanımlanmıştır (Anonim, 2017).

Tüketicinin bir ürünü satın almasında gösterdiği duyarlılık pek çok faktörden etkilenmektedir. Tüketicilerin gıda etiket bilgilerine yönelik tutumlarının sosyo-ekonomik özelliklere göre farkl1lık gösterdiği yapılan araştırmalarla tespit edilmiştir (Coşkun ve Kayışoğlu, 2018; Gökçen ve Küşümler, 2021). Tüketicilerin gida tercihi yapmalarında önemli role sahip olan etiket bilgileri, firmalar tarafından da müşteri sadakatini sağlama aracı olarak kullanılmaktadır. Bu nedenle, değişen tüketici profillerine göre istek ve beklentileri cevaplandırabilmek için, firmalar tüketicilerin güncel hayat tutumlarına ilişkin ürün satın alma süreçlerini göz önüne almalıdırlar (Sarıtaş, 2018).

Tüketici talepleri doğrultusunda, firmaların pazarlama stratejilerini geliştirmeleri için tüketici duyarlılığını inceleyen araştırmalara daha fazla ihtiyaç vardır. Tüketici odaklı bu tür araştırmalar, sürekli değişen ve yenilenen tüketici tutum ve davranışlarına yönelik güncel verilerin tespit edilmesi bakımından önemlidir. Bu araştırmada, Samsun ili kentsel alanda ikamet eden tüketicilerin gıda ambalajı üzerindeki etiket bilgilerine ve logolara yönelik duyarlılıkları belirlenmiştir. Araştırmayla, tüketicilere ait sosyo-ekonomik özelliklerin yanı sıra, g1da etiket bilgilerini inceleme sıklıkları ve gıda etiketinde yer alan logolara ilişkin bilgi düzeylerinin belirlenmesi hedeflenmiştir.

\section{Materyal ve Yöntem}

Araştırmanın materyalini, Samsun ili merkezinde yer alan Atakum, Canik ve İlkadım ilçelerinin kentsel alanında ikamet eden tüketicilerle yapılan anketlerden elde edilen veriler oluşturmaktadır. Anketler 2021 yılının Ocak-Şubat aylarında tamamlanmıştır. Anket yapılan tüketici sayısının belirlenmesinde ise Cochran örnekleme formülü (Eşitlik 1) kullanılmıştır (Barlett ve ark., 2001).

$$
n=\frac{(t)^{2}(p)(q)}{(d)^{2}}, \quad n=\frac{(1.96)^{2}(0.5)(0.5)}{(0.05)^{2}}=384
$$

Eşitlikte n, örnek hacmini; $t$, \% 95 güven derecesine karşılık gelen tablo değerini; $p$, incelenen olayın meydana gelme olasılı̆̆ını $(0.5) ; q$, incelenen olayın meydana gelmeme olasılı̆̆ını $(0.5) ; d$, izin verilen hata payını (\% 5) ifade etmektedir. Buna göre, anket yapılan tüketici sayısı 384 olarak belirlenmiştir.

Araştırmanın amacına uygun şekilde hazırlanan anket formunda, açık ve kapalı uçlu sorular ile beşli likert ölçeği şeklinde (kesinlikle katılmıyorum: 1, katılmıyorum: 2, kararsızım: 3, katılıyorum: 4, kesinlikle katılıyorum: 5) hazırlanmış sorular yer almaktadır. Tüketicilerin gida etiket bilgilerine karş1 gösterdikleri duyarlılık, Tablo 1'de yer alan logolardan hareketle ölçülmüştür. Bunun için tüketicilere söz konusu logoları daha önce görüp görmedikleri sorulmuş, ilgili logoyu gördüğünü ifade eden tüketicilerden logonun neyi ifade ettiğini tanımlamaları istenmiştir. Araştırmadan elde edilen verilerin analiz edilmesinde frekans, yüzde ve ortalama gibi tanımlayıc1 istatistiklerden yararlanılmıştır. 
Tablo 1. Gıda ambalajı üzerindeki logolara ait tanımlar Table 1. Definitions of logos on food packaging

\begin{tabular}{|c|c|}
\hline & $\begin{array}{l}\text { Türk Standardları Enstitüsü'nün kısaltmasıdır. Logo, kalite standartlarının yerine getirildiğini } \\
\text { ifade eder. }\end{array}$ \\
\hline & Helal gida logosudur. Logo, İslami koşullara uygunluğu ifade eder. \\
\hline & $\begin{array}{l}\text { Geri kazanılabilir ambalaj logosudur. Logo, ambalaj atıklarının geri toplanması, tekrar } \\
\text { kullanılması, geri kazanımının kolaylaştırılması ve tüketicinin bilgilendirilmesini amaçlar. }\end{array}$ \\
\hline & $\begin{array}{l}\text { Organik tarım logosudur. Logo, tarımsal üretimde kimyasal girdi uygulamaları yapılmadan izin } \\
\text { verilen içerikteki ürünler kullanılarak, üretimden tüketime her aşamanın kontrollü olduğunu } \\
\text { ifade eder. }\end{array}$ \\
\hline & $\begin{array}{l}\text { İyi tarım uygulamaları logosudur. Logo, çevre, insan ve hayvan sağlığına zarar vermeyecek } \\
\text { ölçüde tarımsal üretimin yapılması, doğal kaynakların korunması, tarımda izlenebilirlik ve } \\
\text { sürdürülebilirlik ile güvenilir ürün arzının sağlanmasını ifade eder. }\end{array}$ \\
\hline & $\begin{array}{l}\text { Döngülerin içindeki sayılar, ürün için kullanılan plastik tipini ve geri dönüştürülüp } \\
\text { dönüştürülemeyeceğini belirtmek için kullanılır. }\end{array}$ \\
\hline & $\begin{array}{l}\text { Yeşil nokta logosudur. Logo, ambalajın geri kazanım sorumluluğunun, o ülkedeki Yeşil Nokta } \\
\text { Örgütü Üyesi kuruluşa ait olduğunu ifade eder. }\end{array}$ \\
\hline & $\begin{array}{l}\text { Logo, ürünün EN 13432/14955 Avrupa standardına göre endüstriyel olarak kompostlanabilir } \\
\text { olduğunu ifade eder. }\end{array}$ \\
\hline
\end{tabular}

\section{Bulgular ve Tartışma}

Samsun ili kentsel alanda anket yapılan tüketicilerin yaşı 18-80 yıl arasında değişmekte olup, ortalama yaş 36.7 'dir. Tüketicilerin tamamı en az ilkokul düzeyinde öğrenim görmüş, ortalama eğitim süresi 13 y1l olarak tespit edilmiştir. Tüketici ailesi ortalama 3.9 kişiden oluşmaktadır. Ailelerde 6 yaşın altında ortalama 0.3 kişi, 65 yaşın üzerinde 0.3 kişi ve bakıma muhtaç 0.1 kişi bulunmaktadır. Hanedeki 6 yaşın altı, 65 yaşın üstü ve bakıma muhtaç kişilerden oluşan nüfus hane halkının yaklaşık \% 18'ini oluşturmaktadır (Tablo 2).

Tüketicinin bir ürünü satın alma kararında, ambalaj üzerindeki etiket bilgilerinin etkisi oldukça fazladır. G1dalarda kullanılan katkı maddelerinin insan sağlığına verdiği zararlar, gıdalardaki etiket bilgilerini önemli hale getirmektedir. Gıda etiketinde yer alan bilgilerin incelenmesi konusundaki duyarlılık, tüketicilerin gida satın alma tercihini ve bu tercihi yaparken gida kontrolü, sağlıklı beslenme ve gida güvenliği gibi konulardaki tutum ve davranışlarının ne yönde olduğunu göstermektedir. Araştırma kapsamında anket yapılan tüketiciler, g1da satın alırken 4.50 ortalama değerle en fazla son kullanma tarihine bakmaktadır. Son kullanma tarihine genellikle (\% 19.5) ve her zaman (\% 69.5) bakanların oranı toplam \% 89'dur. Araştırmada, tüketici duyarlılığı açısından son kullanma tarihinden sonra ambalaj dayanıklılığı ikinci (4.11) ve ürün adı üçüncü sırada (3.92) yer almaktadır. Tüketicilerin en az dikkat ettikleri etiket bilgileri ise sirasıyla; seri/parti numarası (2.20), ithalat kontrol belgesi tarihi (2.25) ve üretim izin tarihidir (2.96) (Tablo 3). Daha önce yapılan pek çok araştırmada da, tüketicilerin gıda satın alırken etiket bilgilerinden en fazla son kullanma tarihine dikkat ettikleri ortaya konulmuştur (Güneş ve ark., 2014; Salicik ve Kumral., 2017; Gül ve Dikmen, 2018; Kılıç ve ark., 2020; Sezgin ve ark., 2020).

G1da ambalajı üzerindeki logolar konusunda duyarlı olan tüketicilerin, gida satın alırken logolara dikkat etmesi ve buna göre gıdaların güvenilirliğini sorgulaması beklenir. Ancak araştırma sonuçları, tüketicilerin gıda etiketindeki logolara yönelik bilgi eksikliğinin yüksek, farkındalığın ise düşük olduğunu ortaya koymaktadır. $\mathrm{Bu}$ durum, tüketicilerin en iyi bildiği logo olan Türk Standardları Enstitüsü (TSE)'nün bile sadece \% 31.8 oranında doğru tanımlanabilmesinden anlaşılmaktadır. Diğer bilinirliği yüksek logolardan olan helal gidayı tanımlayanların oranı \% 26.6, geri kazanılabilir ambalajı tanımlayanların oranı \% 25.3 olarak tespit edilmiştir. Kompostlanabilir ürün 
Tablo 2. Tüketicilere ait demografik özellikler

Table 2. Demographic characteristics of consumers

\begin{tabular}{lcccc}
\hline & Ortalama & En düşük & En yüksek & Standart sapma \\
\hline Yaş (yıl) & 36.7 & 18 & 80 & 13.0 \\
Eğitim süresi (yıl) & 13.0 & 5 & 23 & 3.7 \\
Hane halkı büyüklüğü & 3.9 & 1 & 13 & 1.6 \\
6 yaşın altındaki çocuk & 0.3 & 0 & 4 & 0.6 \\
65 yaş üstü kişi & 0.3 & 0 & 3 & 0.6 \\
Bakıma muhtaç kişi & 0.1 & 0 & 2 & 0.3 \\
Bireysel gelir (TL/ay) & 3255.0 & 0 & 25000 & 2891.5 \\
Hane halk1 geliri (TL/ay) & 6078.7 & 1000 & 40000 & 3719.5 \\
\hline
\end{tabular}

Tablo 3. Gıda ambalaj özelliği ve etiket bilgisine yönelik tüketicilerin duyarlılığı

Table 3. Consumer awareness about food packaging feature and label information

\begin{tabular}{|c|c|c|c|c|c|c|c|c|c|c|c|}
\hline & \multicolumn{2}{|c|}{ Hiçbir zaman } & \multicolumn{2}{|c|}{ Nadiren } & \multicolumn{2}{|c|}{ Ara sira } & \multicolumn{2}{|c|}{ Genellikle } & \multicolumn{2}{|c|}{ Her zaman } & \multirow{2}{*}{ Ortalama* } \\
\hline & Say1 & $(\%)$ & Say1 & $(\%)$ & Say1 & $(\%)$ & Say1 & $(\%)$ & Say1 & $(\%)$ & \\
\hline Son kullanma tarihi & 13 & 3.4 & 7 & 1.8 & 22 & 5.8 & 75 & 19.5 & 267 & 69.5 & 4.50 \\
\hline Ambalaj dayanıklılı̆g 1 & 7 & 1.8 & 33 & 8.6 & 33 & 8.6 & 148 & 38.5 & 163 & 42.5 & 4.11 \\
\hline Ürün adı & 30 & 7.8 & 27 & 7.0 & 48 & 12.5 & 116 & 30.2 & 163 & 42.5 & 3.92 \\
\hline İçindekiler & 18 & 4.7 & 31 & 8.1 & 81 & 21.1 & 130 & 33.8 & 124 & 32.3 & 3.81 \\
\hline $\begin{array}{l}\text { Muhafaza ve kullanım } \\
\text { bilgileri }\end{array}$ & 28 & 7.3 & 42 & 10.9 & 52 & 13.6 & 126 & 32.8 & 136 & 35.4 & 3.78 \\
\hline Net miktarı & 25 & 6.5 & 44 & 11.4 & 92 & 24.0 & 124 & 32.3 & 99 & 25.8 & 3.59 \\
\hline $\begin{array}{l}\text { Ambalajın açılır kapanır } \\
\text { olması }\end{array}$ & 32 & 8.3 & 44 & 11.5 & 78 & 20.3 & 154 & 40.1 & 76 & 19.8 & 3.52 \\
\hline Üretici firma & 51 & 13.3 & 53 & 13.8 & 60 & 15.6 & 105 & 27.3 & 115 & 30.0 & 3.47 \\
\hline Ürünün ait olduğu ülke & 61 & 15.9 & 74 & 19.3 & 68 & 17.7 & 86 & 22.4 & 95 & 24.7 & 3.21 \\
\hline Üretim izin tarihi & 97 & 25.2 & 74 & 19.3 & 54 & 14.1 & 66 & 17.2 & 93 & 24.2 & 2.96 \\
\hline $\begin{array}{l}\text { İthalat kontrol belgesi } \\
\text { tarihi }\end{array}$ & 172 & 44.8 & 74 & 19.3 & 51 & 13.3 & 45 & 11.7 & 42 & 10.9 & 2.25 \\
\hline Seri/parti numaras1 & 162 & 42.2 & 86 & 22.4 & 68 & 17.7 & 35 & 9.1 & 33 & 8.6 & 2.20 \\
\hline
\end{tabular}

(\% 1.3) ve yeşil nokta (\% 1.6) logolarını doğru tanımlayan tüketicilerin oranı ise oldukça düşüktür (Tablo 4). İzmir ilinde yapılan bir araştırmada, tüketicilerin \% 46.9'u ürün satın alırken çevreyle ilgili etiket bilgilerini okuduklarını ifade etmişlerdir (Aracıŏlu ve Tatlıdil, 2009). Kahramanmaraş ilinde yapılan bir araştırmada da, tüketicilerin \% 40.96'sının ambalajın geri dönüștürülebilir bir malzemeden üretildiğini gösteren simgeyi bildikleri tespit edilmiştir (Şahin ve ark., 2016). Giresun ilinde yapılan bir araştırma sonucuna göre, tüketicilerin bildikleri markalarda ambalajların tekrar kullanılabilirliği için \% $10-15$ oranında fazladan bir bedel ödemeye istekli olduklarını göstermektedir (Kuru ve Boyraz, 2020). Adiyaman ilinde yapılan bir araştırmada, helal gıda logosuna sahip gıdaların tüketicilerin satın alma davranışına pozitif etkisinin olduğu tespit edilmiştir (Yorulmaz ve Akçi, 2020). Kahramanmaraş ilinde yapılan bir araştırmaya göre, tüketicilerin \% 76'sı helal gıda konusunda bilgi sahibi olmalarına rağmen, gıda satın alırken helal gida logosuna bakanların oranı sadece \% 27.9'dur (Çukadar, 2017).

\section{Sonuç ve Öneriler}

Tüketicinin satın alma süreci ekonomik, sosyal, kültürel ve psikolojik olmak üzere pek çok faktörden etkilendiği için, birbirinden farklı tutum ve davranış gösteren tüketicilerle karşılaşılmaktadır. Satın almada gösterilen bu tutum ve davranışlar sadece farklı kültürlerde değil, aynı kültürel değere sahip bireyler arasında da belirgin farklılıklar gösterebilmektedir. Tüketicinin satın alma sürecini etkileyen faktörlerin tespit edilmesi, birbirinden oldukça farklı tüketici istek ve beklentilerinin karşılanması açısından önemlidir. Tüketici tatmininin sağlanması, rekabet üstünlüğü açısından tüm firmaların öncelikli konuları arasında yer almaktadır. $\mathrm{Bu}$ nedenle değişen sosyoekonomik koşullarla birlikte tüketici duyarlılığının ne şekilde değiştiğinin belirlenmesi için, tüketicilerin satın alma kararını verirken sergiledikleri davranışın bilimsel yöntemlerle analiz edilmesi gerekir.

Samsun ili kentsel alanda yaşayan tüketicilerin gıda ambalajındaki etiket bilgilerine ve logolara 
Tablo 4. Gıda logoları hakkında tüketici bilgisi

Table 4. Consumer information about food logos

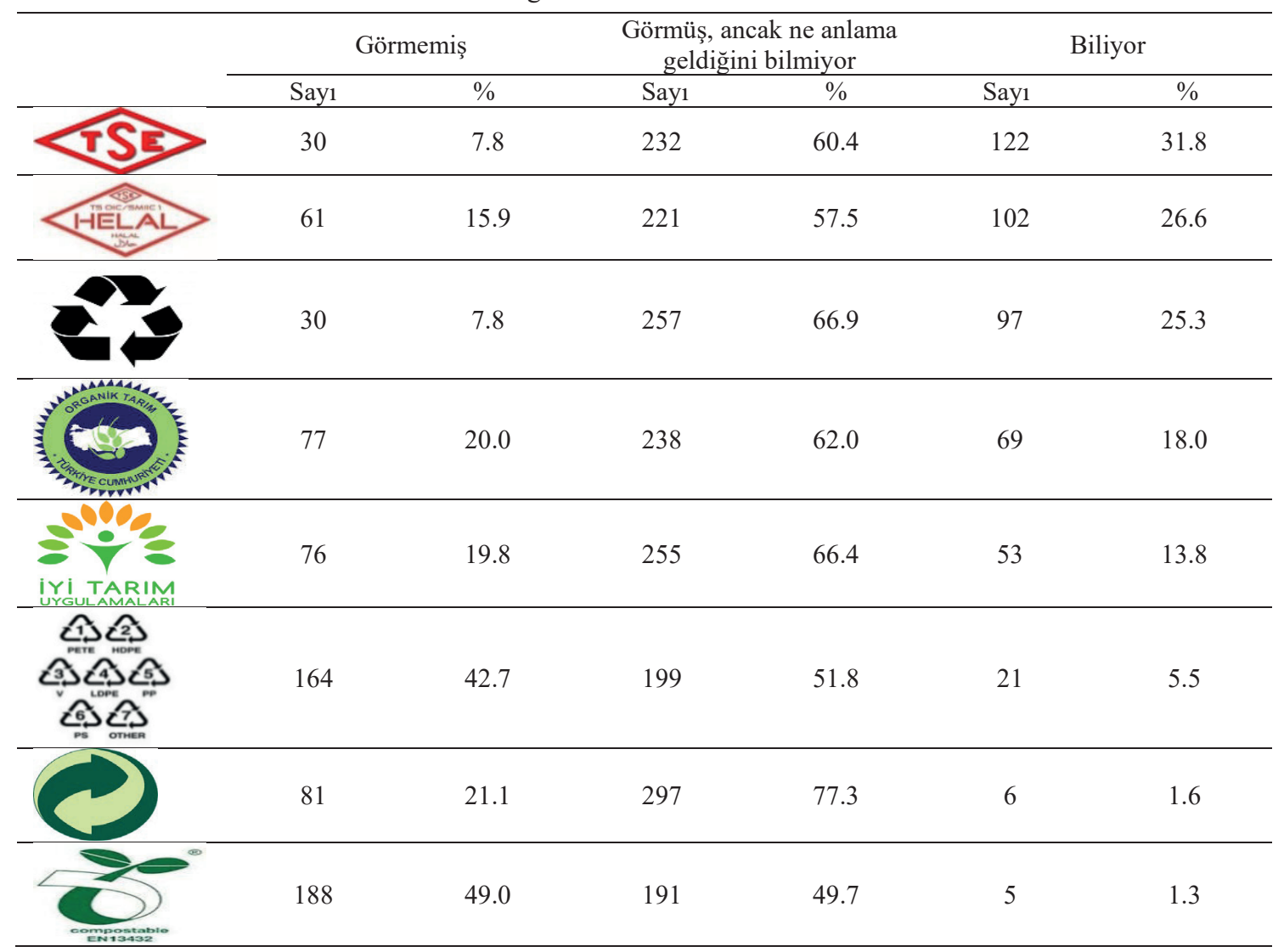

yönelik duyarlılıklarını ele alan bu araştırma sonuçlarına göre, son kullanma tarihi gıda satın alırken en fazla dikkat edilen etiket bilgisidir. Hâlbuki gıda satın alma kararı verilirken, sadece son kullanma tarihi değil; insan sağlığını doğrudan ilgilendiren ambalaj üzerindeki içindekiler, muhafaza ve kullanım bilgileri gibi konuların da dikkate alınması gerekir. Gıda satın alma sürecinde dikkat edilmesi gereken konularla ilgili olarak tüketicilerin bilinçlendirilmesinde televizyon ve internet gibi kitle iletişim araçları aracılığıyla uzman katılımının sağlandığı programlara ağırlık verilmesi etkili bir yöntem olacaktır. Ayrıca okullarda öğrencilere sağlıklı beslenmeyle ilgili verilecek eğitimlerde gidaların satın alma aşamalarında dikkat edilecek konular üzerinde durulmalıdır. Tüketicilerin bilinçli olmaları, üretimden başlamak üzere gıdaların tüketiciyle buluşana kadarki süreçte sorumlu olan tüm firmaların da daha dikkatli hareket etmelerini sağlayacaktır. Tüketicilerin temel haklarının bilincine varması ve gidalarla ilgili sorun yaşadığında yapması gerekenlerden haberdar olması önemlidir. Zira haklarını ve bu hakları nasıl kullanacağını bilmeyen tüketicilerin davranışları, firmalara etik kurallara uymama konusunda cesaret verecektir. $\mathrm{Bu}$ nedenle tüketiciler, bireysel ya da örgütlenerek haklarının en temel savunucusu olmak ve bunun için mücadele etmek zorundadır.

Araştırmadan elde edilen önemli sonuçlardan biri de, gida ambalajı üzerinde bulunan logolardan olan ve her üç tüketiciden sadece biri tarafindan doğru tanımlanan TSE'nin en bilinir logo olmasıdır. $\mathrm{Bu}$ sonuç, tüketicilerin logolar konusundaki bilinç düzeylerinin düşük olduğunu göstermektedir. Tüketicilerin alternatif gıdalar arasındaki tercihinde, uzmanların bazı logolara özellikle dikkat etmelerine yönelik tavsiyeleri olumlu etki yaratabilir. Ancak, sinırlı geliri olan tüketicilerin etiket bilgilerine ya da logolara bakmak yerine, ucuz olan ürüne yönelme davranışları yadırganmamalıdır. Bu nedenle tüketicilerin satın alma davranışları incelenirken, sadece etiket bilgileri ve logolara karşı duyarlılık değil, ekonomik faktörlerin etkisinin de değerlendirilmesi gerekir. Nitekim toplumsal anlamdaki bilinçlenmeyle birlikte, ekonomik anlamda iyileştirmeye de ihtiyaç vardır.

\section{Kaynaklar}

Akgüngör, S., Trijp, H.V., Herpen, E.V., Gülcan, Y., Kuştepeli, Y., 2011. Gıda etiketlerine yönelik dikkat ve algı: Dokuz Eylül Üniversitesi'nde uygulanan göz 
hareketleri izleme deneyi sonuçları. Dokuz Eylül Üniversitesi Sosyal Bilimler Enstitüsü Dergisi, 13(3): 7-18.

Anonim, 2017. Türk Gıda Kodeksi Gıda Etiketleme ve Tüketicileri Bilgilendirme Yönetmeliği. Resmi Gazete Sayı: 29960 (Mükerrer), 26 Ocak 2017.

Aracıŏlu, B., Tatlıdil, R., 2009. Tüketicilerin satın alma davranışında çevre bilincinin etkileri. Ege Akademik Bakış, 9(2): 435-461.

Barlett, J.E., Kotrlik, J.W., Higgins, C.C., 2001. Organizational research: Determining appropriate sample size in survey research. Information Technology, Learning, and Performance Journal, 19(1): 43-50.

Coșkun, F., Kayışoğlu, S., 2018. Besin etiketi okuma alışkanlıklarına ve etiket okumanın satın alma tercihlerine cinsiyetin etkisi: Tekirdağ ili örneği. Akademik Glda, 16(4): 422-430.

Çukadar, M., 2017. Helal gıda konusunda tüketici davranışları. Gaziosmanpaşa Üniversitesi Ziraat Fakültesi Dergisi, 34(3): 190-200.

Gökçen, M., Küşümler, A.S., 2021. Yetişkinlerde gıda etiketi okuma bilgi düzeyi ile davranışa geçirme arasındaki ilişki. Online Türk Sağlık Bilimleri Dergisi, 6(1): 82-91.

Gül, F., Dikmen, D., 2018. Kadın tüketicilerde besin etiketi okuma alışkanlıkları ve alerjen bilgi düzeyinin saptanması. Beslenme Diyet Dergisi, 46(2): 157-165.

Güneș, F.E., Aktaç, Ş., Korkmaz, B.İ.O., 2014. Tüketicilerin gida etiketlerine yönelik tutum ve davranışları. Akademik Gida, 12(3): 30-37.
Kılıç, O., Boz, İ., Ery1lmaz, G.A., 2020. Determination of consumers' behaviors in food purchasing, conservation, consumption and food safety. Yönetim ve Ekonomi Araştırmaları Dergisi, 18(2): 29-40.

Kuru, Ö., Boyraz, E., 2020. Hepinizi yeni bir ürün gibi görüyorum! Tekrar kullanılabilir ambalajlara yönelik tüketici tutumları. Kafkas Üniversitesi İktisadi ve Idari Bilimler Fakültesi, 11(22): 646-668.

Salicik, D., Kumral, A.Y., 2017. Bursa ili kentsel alanında tüketicilerin güvenilir gıda tüketimine yönelik tutumlarının belirlenmesi. Uludă̆ Üniversitesi Ziraat Fakültesi Dergisi, 31(2): 69-82.

Sarıtaş, A., 2018. Yeşil satın alma davranışının algılanan tüketici etkinliğine etkisinde çevresel kaygının aracılık rolü. Sosyal Araştırmalar ve Davranış Bilimleri Dergisi, 4(5): 47-71.

Sezgin, A.C., Ayyıldı,, S., Durmaz, N.E., 2020. Gastronomi ve mutfak sanatları öğrencilerinin gıda etiketlerini okuma düzeyleri. Uluslararasi Toplum Araştırmaları Dergisi, 16(29 Ekim Özel Say1s1): 3321-3343.

Şahin, A., Meral, H., Aytop, Y., 2016. Yeşil pazarlamada tüketici algısi: Kahramanmaraş kent merkezi örneği. Anadolu Tartm Bilimleri Dergisi, 31(1): 60-71.

Yorulmaz, D.Ö., Akçi, Y., 2020. Helal gida tüketimine yönelik tutumların satın alma niyeti üzerindeki etkisi (Adıyaman örneği). Kahramanmaraş Sütçü İmam Üniversitesi Sosyal Bilimler Dergisi, 17(2): 12181238. 